\title{
EDUCAÇÃO AMBIENTAL E A ECOPEDAGOGIA NO PROCESSO DE ENSINO E APRENDIZAGEM ${ }^{1}$
}

\author{
Daniele Gonçalves da Silva, Universidade Federal do Rio de Janeiro, UFCG, \\ danielly_ip@hotmail.com
}

\begin{abstract}
RESUMO
O presente estudo busca apresentar um olhar sobre a educação ambiental, a ecopedagogia e sua importância na construção da consciência ambiental das crianças. Surge da inquietação da autora em observar como está acontecendo nos espaços escolares - espaço educacional construtor de saberes e desenvolvimentos. Temos como objetivo do estudo discutir e procurar compreender o processo de ensino e aprendizagem na implantação da Educação Ambiental e a presença da ecopedagogia nos espaços escolares, que se faz como um processo que visa a sustentabilidade e seu desenvolvimento através das interações e vivencias do dia a dia. Temos como pressuposto a educação como um papel imprescindível no processo de mudanças frente às problemáticas que atinge a sociedade em seus diversos aspectos. Neste sentido, a educação ambiental deve está presente dentro do panorama escolar, associada com a educação formal e não formal e de forma interdisciplinar, em que os professores precisam conhecê-la e organizá-la, visando buscar soluções e criando ações participativas e perceptivas na relação da natureza e o homem. O método será pautado na proposta de abordagem qualitativa, ou seja, na perspectiva fenomenológica-hermenêutica.
\end{abstract}

\section{PALAVRAS-CHAVE: educação ambiental; ecopedagogia; ensino e aprendizagem.}

\begin{abstract}
The present study seeks to present a look at environmental education, ecopedagogy and its importance in the construction of environmental awareness of children. It arises from the author's concern to observe how it is happening in school spaces - educational space that builds knowledge and development. We aim to discuss and seek to understand the teaching and learning process in the implementation of Environmental Education and the presence of ecopedagogy in school spaces, which is done as a process that aims at sustainability and its development through the interactions and experiences of the day to day. We have as a presupposition education as an essential role in the process of changes in relation to the problems that affect society in its various aspects. In this sense, environmental education must be present within the school landscape, associated with formal and non-formal education and in an interdisciplinary way, in which teachers need to know and organize it, seeking solutions and creating participatory and perceptive actions in the Relationship of nature and man. The method will be based on the proposal of a qualitative approach, that is, from the phenomenological-hermeneutic perspective.
\end{abstract}

KEYWORDS: environmental education; Ecopedagogy; teaching and learning;

\footnotetext{
${ }^{1} \mathrm{O}$ presente trabalho (não) contou com apoio financeiro de nenhuma natureza para sua realização.
} 


\section{RESUMEN}

El presente estudio busca presentar una mirada sobre la educación ambiental, la ecopedagogía y su importancia en la construcción de la conciencia ambiental de los niños. Se plantea la inquietud de la autora en observar cómo está sucediendo en los espacios escolares - espacio educativo constructor de saberes y desarrollos. Con el objetivo del estudio discutir y tratar de comprender el proceso de enseñanza y aprendizaje en la implantación de la Educación Ambiental y la presencia de la ecopedagogía en los espacios escolares, que se hace como un proceso que busca la sustentabilidad y su desarrollo a través de las interacciones y vivencias del día a día En el día. Tenemos como presupuesto la educación como un papel imprescindible en el proceso de cambios frente a las problemáticas que afecta a la sociedad en sus diversos aspectos. En este sentido, la educación ambiental debe estar presente dentro del panorama escolar, asociada con la educación formal y no formal y de forma interdisciplinaria, en que los profesores necesitan conocerla y organizarla, buscando buscar soluciones y creando acciones participativas y perceptivas en la sociedad La relación de la naturaleza y el hombre. El método será pautado en la propuesta de abordaje cualitativo, o sea, en la perspectiva fenomenológica-hermenéutica.

PALABRAS CLAVES: educación ambiental; Ecopedagogía; Enseñanza y aprendizaje.

\section{INTRODUÇÃO}

O tema desse estudo versa sobre a educação ambiental e a eco pedagogia. A preocupação com a Educação Ambiental (EA) atualmente está em evidência, em razão da percepção tanto de cientistas como do sujeito ordinário que a vida planetária vem sofrendo consequências climáticas, saúde, psíquicas devido à degradação do meio ambiente (MA). Portanto, se faz meritório discutir a vida pautada na conscientização do homem sobre sua preservação.

Uma das propostas advém de Jacobi sobre conscientizar a população sobre os danos irreversíveis que pequenas ações podem causar no MA. Daí se sustenta a educação ambiental como um meio importantíssimo para disseminação de conhecimentos e conscientização dos alunos, que foi assegurada pela lei 9795/99 de 27 de abril de 1999. Lei essa que prevê a promoção da educação ambiental em todos os níveis de ensino, podendo acontecer através de ações e estímulos que possibilitem a preservação do meio. Dessa maneira, pode-se ver a EA como direito e dever de todos; o governo deve garantir os direitos aos cidadãos, porem os 
cidadãos devem cumprir seus deveres, para que dessa forma possa haver pessoas conscientes, um meio ambiente preservado e com ações que procurem promover a recuperação do que já não pode ser mais mudado. Portanto, a educação ambiental deve ser pensada no passado, presente e futuro.

Para trabalhar a EA nos espaços escolares, faz-se necessárias diversas ações e discussões para sua melhor disseminação, assim a ecopedagogia surge como um processo facilitador e necessário nos espaços escolares dentro dessa temática. A ecopedagogia não surge como uma nova teoria da educação, mas como um processo e concepção, que estará direcionada a sustentabilidade e a uma nova visão do trabalho com a educação ambiental, priorizando as interações e vivências do dia a dia, a humanização. Está ligada diretamente com a sustentabilidade, pautadas na ideia de que devemos buscar a conscientização desde cedo, para preservar o presente pensando no futuro, trabalhando assim com quem será o futuro do nosso planeta. Para entender a ecopedagogia precisamos nos pautar na sustentabilidade, ambas estão interligadas em prol de um objetivo maior que é pensar o meio ambiente cotidianamente, de forma a reeducar as pessoas através de meios concretos, que busquem a consciência ecológica de forma democrática, partindo da ética.

Considerando-se a importância da discussão e presença da Educação Ambiental para a formação da criança, este trabalho ressalta a relevância da realidade de uma Educação Ambiental apropriada e existente na escola, capaz de formar seres com aprendizagens concretas de seu importante papel na preservação e reconstrução do meio ambiente, como também a presença da ecopedagogia nos espaços escolares, a eco pedagogia um novo processo que visa a sustentabilidade e seu desenvolvimento através das interações e vivencias do dia a dia.

Logo, a escola é o espaço em que se deve ter uma maior discursão e presença da EA, pois a mesma consiste como sendo um espaço educacional construtor de saberes e desenvolvimentos. E nela que as crianças podem construir aprendizagens que acompanharão por toda sua vida, e a educação tem um papel indispensável no processo de mudanças diante às problemáticas que abrange a sociedade em seus diversos aspectos. A diretriz curricular do ensino fundamental I, traz que a escola deve oferecer em suas praticas pedagógicas os princípios Éticos da autonomia da responsabilidade, solidariedade e do respeito ao bem comum. Para compor tais princípios entram outros de grande valia para sustentá-los, como os 
políticos afetos aos Direitos e Deveres de Cidadania, do exercício da criticidade e do respeito à Ordem Democrática.

Dessa forma a educação ambiental deve estar presente nas escolas garantindo os preceitos éticos da autonomia e responsabilidade, construindo sujeitos críticos, autônomos e conscientes de seu papel no meio em que vivem. Dessa forma, utilizamos para realização desse estudo alguns autores, estudos e seus entendimentos sobre a educação ambiental e a ecopedagogia, como também sua importante contribuição no processo de ensino e aprendizagem dos alunos, como Pelicionni, Isabel Cristina, Gadotti, Nunes Gatti e Jacobi.

Diante do exposto assinalamos que nosso desenho metodológico coaduna com a perspectiva da pesquisa qualitativa (CRESWELL, 2007, GÜNTHER, 2006, NOVIKOFF, 2010), ou seja, uma pesquisa de caráter teórico, com o propósito de aprofundar na discussão acerca da educação ambiental.

\section{REFERÊNCIAS BIBLIOGRÁFICAS}

CRESWELL, J. W. Projeto de Pesquisa: métodos qualitativo, quantitativo e misto. Porto Alegre: Artmed, 2007.

. Dimensões Novikoff: um constructo para o ensino-aprendizado da pesquisa. In ROCHA, J. G. e NOVIKOFF, C. (orgs.). Desafios da práxis educacional à promoção humana na contemporaneidade. Rio de Janeiro: Espalha fato Comunicação, p. 211-242, 2010a.

GATTI. Bernadete A. Formação de professores no Brasil: características e problemas. Educ. Soc., Campinas, v. 31, n. 113, p. 1355-1379, out. Dez. 2010. Disponível em http://www.cedes.unicamp.br

GADOTTI, Moacir. Pedagogia da terra: Ecopedagogia e educação sustentável Paulo Freire. CLACSO, Consejo Latinoamericano de Ciencias Sociales. Buenos Aires,2001. Disponível em<http://bibliotecavirtual.clacso.org.ar/clacso/gt/20101010031842/4gadotti.pdf $>$ Acessado no dia 20/06/2017.

GÜNTHER, Hartmut. Pesquisa Qualitativa Versus Pesquisa Quantitativa: Esta É a Questão? Psicologia: Teoria e Pesquisa. Mai-Ago 2006, Vol. 22 n. 2, pp. 201-210.

JACOBI, Pedro. Educação ambiental, cidadania e sustentabilidade, 2003. Disponível em <http://www.scielo.br/pdf/cp/n118/16834.pdf>. Acessado no dia 24/02/2017.

Presidência da República. Casa Civil. LEI No 9.795, DE 27 DE ABRIL DE 1999. Disponível em <http://www.planalto.gov.br/ccivil_03/leis/L9795.htm->. Acessado no dia 11/02/2017. 
